\title{
The epidemiological situation in the Americas
}

\author{
CP MOTTA \\ WHO-Pan American Health Organization, Washington D.C., U.S.A.
}

Leprosy was introduced into the Americas by Spanish, Portuguese and other settlers. The historical evidence indicates that the indigenous population was free of the disease.

Pesce (1) studying the Inca pottery and monies did not find any lesions suggestive of leprosy, but many cases were, clearly, leishmaniasis or 'spundia'. The first confirmed case was described at the beginning of the 16th century in Colombia (2), namely the Spanish conqueror and founder of Bogota - Don Gonzalo Jimenez de Quesada. The first leprosarium was established in 1530 (Cartagena, Colombian Caribbean Coast). At that time most of the patients were negro slaves. There is some controversy about the role of Africans in introducing the disease in the Americas: The slave traders were very strict in selecting individuals for shipment (only first class ebony people). Nevertheless, the negro slave population that, in colonial times, outnumbered the white settlers, played an important role in the spreading of the endemy.

During the last four centuries many foci appeared and were always connected with land settlement and migratory flows. However, the most important focus in the Americas - the Amazon sub-region - is of relatively recent origin: the first case was diagnosed at the end of the 19th century (1).

Magnitude and extent of the problem

Leprosy is endemic in all the countries of the Americas with the exception of continental Chile and a few territories. Table 1 and the map show the number of registered cases in every country or territory according to the last information received by WHO/PAHO. The data are presented with reserved judgement due to the lack of uniformity in their gathering (criteria for release of control mainly) and poor development of case finding facilities in some countries or territories.

An estimation of the prevalence rates was made taking into account the trends of the disease and status of control programs. 


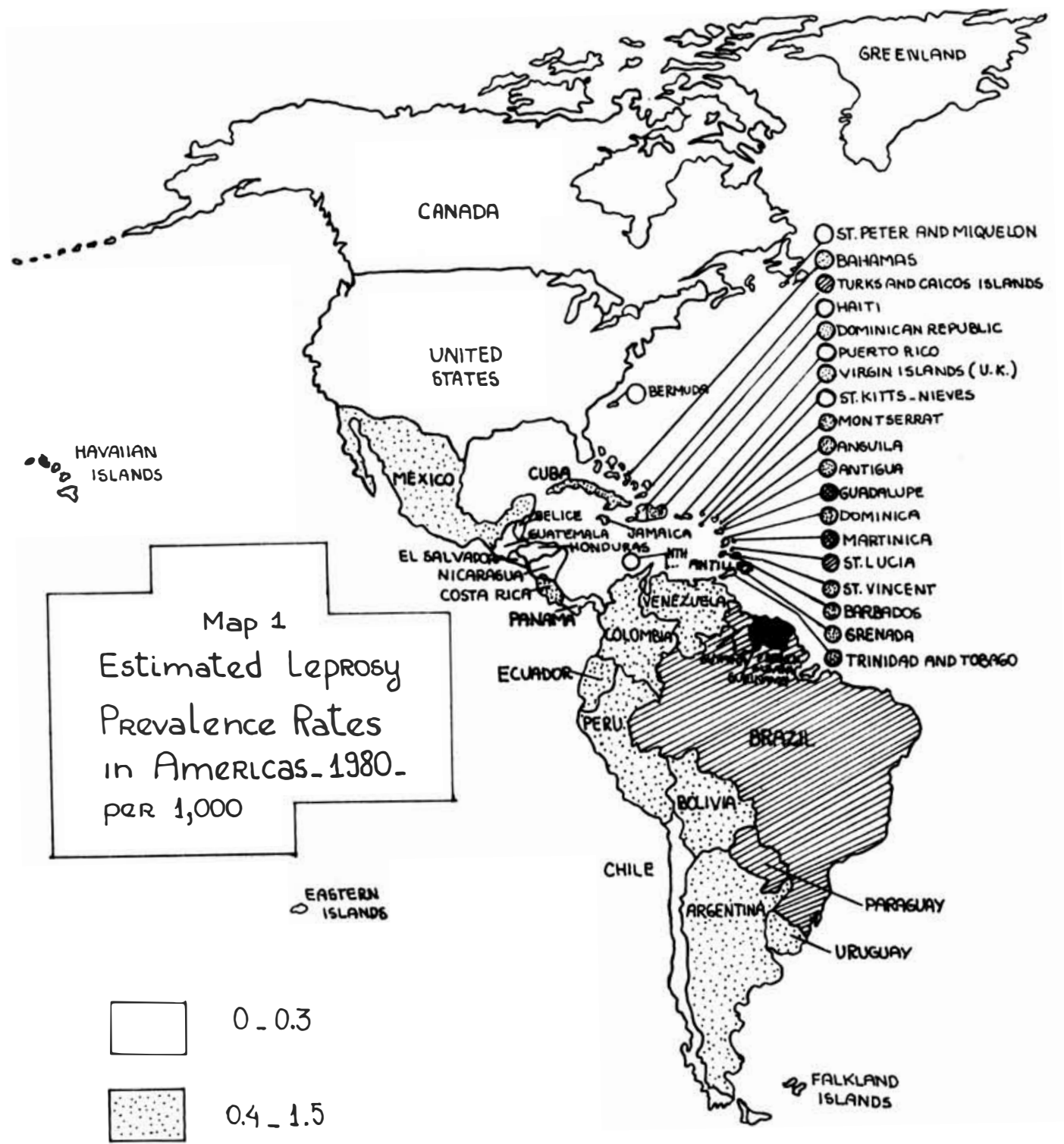

MIII

$1.6-5.0$

$5.1-10.0$

$+10.0$ 


\section{ANDEAN REGION}

In Bolivia leprosy, apparently, is not transmitted in the Andean "altiplano" (about 3,800 meters high) where most of the population is concentrated, but the situation is different in the northwestern part of the country (including the Amazon basin). In 1974 an intensive survey of 32,000 inhabitants (province of Vallegrande, Department of Santa Cruz) disclosed a morbidity rate of 12 per 1000 .

In Colombia, approximately 20,000 cases are undergoing treatment. The principal foci are located in the southeastern branch of the "cordillera" of the Andes. Many patients acquired the disease at an altitude of more than 2,000 meters above sea level.

In Peru more. than $80 \%$ of the patients are infected in the Amazon basin and the principal foci are in the Ucayali River and its tributaries.

In Ecuador most of the cases are from the Pacific coast (provinces of Guayas, Los Rios and El Oro).

In Venezuela the major frequency of cases is at the Andean states on the southeastern leg of the Andean "cordillera" but, also, there are important foci in the southeastern plains (Apure state).

\section{SOUTHERN CONE}

The known cases in Argentina are concentrated in the northeastern provinces of the country and in "greater Buenos Aires" where approximately $70 \%$ of the patients are immigrants from endemic areas.

In Uruguay the registered patients come, for the most part, from the western provinces (Paisandu, Salto and Artigas) bordering the endemic areas of Argentina.

Paraguay has the highest estimated morbidity rates in South America (almost 3 per 1000), and the patients are concentrated in the eastern provinces, including the capital city (Asunción).

Chile presents a peculiar epidemiological situation. Apparently, there is no transmission of leprosy and the few cases reported come from Argentina (Formosa).

The Eastern Island, located 5,000 kilometers from the Pacific coast, with a Polynesian population, has a prevalence rate of about 10 per 1000 .

\section{MEXICO}

Seventy per cent of the notified patients are from the states on the Pacific coast (Colima, Sinaloa, Guanajato, Nayarit, Jalisco) and Michoacan, that is, 6 of the 32 federation unities, all with prevalence rates (of known cases) above 0.5 per 1000 . 
BRAZIL

About $65 \%$ of all registered cases in the Americas come from this country that has $20 \%$ of the continent's population. The geographical distribution of the cases is not uniform. The mordidity rates by regions in 1979 were as follows:

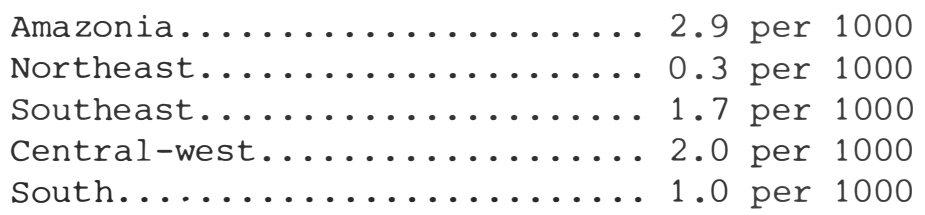

The Brazilian Amazon region represents $6.9 \%$ of the country's general population and has $15.6 \%$ of the registered cases, whereas the southeastern region (Sao Paulo, Minas Gerais, Rio de Janeiro, Espirito Santo), which has $42.4 \%$ of the population, contributes $55.1 \%$ of the cases.

\section{CENTRAL AMERICA}

This area has the lowest frequency of leprosy in the Americas, with the exception of Canada and the United States.

The principal foci are located on the Pacific coast around the "Gulf of Fonseca", the territories of El Salvador, Honduras and Nicaragua, and on the Azuero peninsula in Panama. Only two foci have been identified on the Atlantic coast: Limones in Costa Rica and Bocas del Toro in Panama.

\section{LATIN AMERICA, CARIBBEAN}

In Cuba more than half of the patients live in the eastern provinces (Camaguey, Guantanamo and Oriente Sur).

In the Dominican Republic most of the patients come from the south and east of the country and about 55\% live in Santo Domingo, the capital city.

In Haiti the situation is virutally unknown, but recent surveys have detected many new cases in the northern departments (Artibonite and Cape Hatian).

In Puerto Rico 175 cases were notified from 1949 to 1968 and to this figure must be added 58 patients more detected in New York in persons of Puerto Rican birth.

\section{Caribbean}

The epidemiological situation varies: Some countries or territories have, relatively, high morbidity rates, from 9.1 to 20.2 per 1000 
(Guadalupe, Martinique, Suriname and French Guiana). In the English speaking countries/territories, the highest rates are in St. Lucia (2.9) and Turks/Caicos (4.7). In other countries/territories, the problem appears to be less serious.

North America

In Canada there were 64 registered cases in the period 1972-1976; the average annual number of new cases was 13.

In the United States of America the present register contains 1790 cases and there is an average of 140 new cases each year. The principal foci are in Louisiana, Florida, the states bordering on Mexico (Texas and California primarily) and Hawaii.

\section{Distribution by clinical forms}

According to data gathered by WHO/PAHO, the lepromatous form predominates and contributes about $50 \%$ of the cases.

Nevertheless, the countries /territories with the highest morbidity rates have the lowest percentages of LL cases. The percentage of LL cases is as follows:

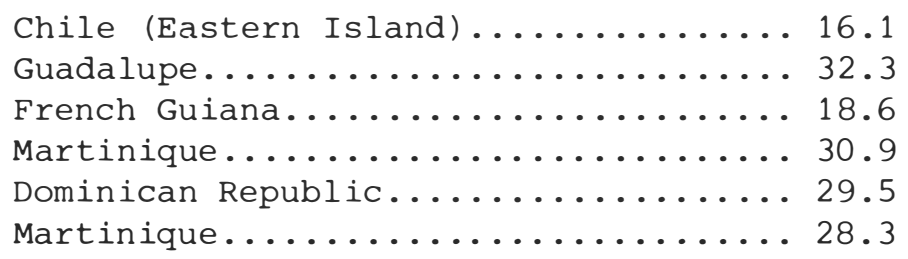

It is important to note two aspects of clinical findings peculiar to the Americas:

1. Lucio's leprosy, exclusive of Mexico and Central America, is a diffuse variety of the lepromatous form. At the onset there is a light pinkish color of the skin (face primarily) with no apparent infiltration. These cases contrast with other individuals in the peasant population which, frequently, have a pale color due to anemia. The skin smear is strongly positive for acid-fast bacilli. Later on, the infiltration and erythema are evident and a complete loss of the eyebrows and eyelashes is observed. The conjunctiva retains its white color because the eye is usually not involved in the process. With the progress of the disease, neuritic lesions may be established, but nodules and tubercules are never seen. This variety of diffuse lepromatous leprosy is prone to reactional episodes similar to erythema nodosum, but the pathological vascular component is more serious leading to necrosis expressed clinically by an ulcer with a triangular shape. 
2. Borderline (dimorphous) cases: The infiltration/edema of the plaques are not so accentuated as those of the African patients and, it seems there are some pathological differences that make it difficult to assess the cases by the Ridley-Jopling classification criteria.

\section{Distribution by age}

As a general rule, the leprosy cases in the Americas are detected after 15 years of age. The disease in children is infrequent - from 2 to $10 \%$ of the cases. Only in the Amazon sub-region does this percentage go up to $17 \%$, and an early establishment of disabling lesions is observed.

\section{$\underline{\text { Distribution by sexes }}$}

Leprosy in the Americas is predominant in males: a sex index of 200 males for 100 females in the lepromatous form. The Dominican Republic is the exception; a small predominance of female cases is reported.

Acceptance of leprosy cases in the community

The stigma associated with the cultural and social categories of "leprosy" and "leper" (or other local names of the disease) is very strong in practically all countries/territories and is the principal constraint that hampers the fight against the endemy. Nevertheless, there are some areas where the stigma was attenuated after proper community information and health education.

\section{Urban leprosy}

The phenomenon of "accelerated urbanization", mainly in Latin America, has diverted the epidemiological situation of the endemy from rural to urban.

An assessment done in Colombia (1960) has disclosed that $70 \%$ of the patients lived in rural areas. But in 1980 (6) $70 \%$ of the treated cases were living in urban areas.

In Brazil in 1975 (5) $36.6 \%$ of the registered patients $(38,326)$ were living in the 9 "metropolitan areas", cities with more than 1,000,000 inhabitants. These areas have $27.1 \%$ of the general population of the country.

Studies are needed to confirm whether the observation expressed by some Latin American leprologists that the propagation of leprosy in urban areas (even in the slum situation) is not so effective as 
in some rural places with scattered population. Is an ecological factor lacking?

\section{Trends of the endemy}

In the few countries where the incidence rates were observed for more than 20 years the impression is, with a single exception (Venezuela), that the endemy is not declining.

In Brazil the number 'of new cases detected each year has steadily increased as well as the incidence rates when taking into account some operational variations.

Also in Cuba, where a efficient case finding and supervised treatment program is being developed, the incidence of new cases (about 3 per 100,000 ) is practicallly the same in each of the last 10 years.

Venezuela is the exception: The incidence of leprosy has decreased $75 \%$ in 25 years.

Summary of the epidemiological situation

The outstanding epidemiological characteristic of leprosy in the Americas is as follows:

1. With the exception of a few countries or territories, half the diagnosed cases are multibacillary forms.

2. The prevalence in children (age group 0-14 years) is less than $10 \%$ of the total cases.

3. Up to the 1950's most of the cases detected came from rural areas (communities with fewer than 2,500 inhabitants or dispersed population). At the present time, there is a reversal of the situation because of the phenomenon of "accelerated urbanization" in Latin America.

4. In general, the frequency of the disease is higher in areas of warm climate and high precipitation, but there are exceptions: for instance, the Colombian and north Ecuadorian Pacific coasts. Some areas of the Andean Cordillera (Colombia, Venezuela) with cool and medium humid climate have relatively high prevalence rates.

5. The leprosy endemicity in the Americas is low when compared with the African or Asian foci. There is a patchy distribution of the cases. Some limited foci (Paraguay, Colombia, Brazil) have prevalence rates up to 24 per 1000 and, in some situations, this pattern cannot be due to factors of land settlement or migratory movements of the population. 
6. In most of the countries/territories the endemicity is not declining, even when the recommended policies of control are applied.

\section{References}

1 Pesce H. Epidemiologia de la lepra en el Peru. University of Lima, Peru: 1963.

2 Montaya y Flores JB. Contribución al estudio de la lepra en Colombia. Medellin, Colombia: 1910.

3 Report from the Communicable Disease Center, Atlanta, Georgia, USA. Leprosy Surveillance. 1970.

4 Brubaker ML. IV Seminario Panamericano sobre el control de la lepra. PAHO Scientific Publication, No 344, 1977.

5 de Mello A. Hanseniase nas areas metropolitanas. Bol Div Nac Derm Sanit (Brazil), XXXVI, No 1, 31-41.

6 Molina E. Personal communication, 1980.

7 El Nuevo Programa de Control de la lepra en Cuba. Ministry of Health Publication, 1978.

Table 1. Leprosy cases on the active register by country, estimated number of patients and prevalence rates.

REGION OF THE AMERICAS - 1980

\begin{tabular}{|c|c|c|c|c|}
\hline \multirow{2}{*}{$\begin{array}{l}\text { Subregions } \\
\text { or Areas }\end{array}$} & \multirow{2}{*}{$\begin{array}{l}\text { Estimated } \\
\text { Population }\end{array}$} & \multirow{2}{*}{$\begin{array}{l}\text { Registered } \\
\text { Cases }\end{array}$} & \multicolumn{2}{|c|}{ Total Estimated } \\
\hline & & & Number & $\begin{array}{c}\text { Rate } \\
\text { per } 1,000\end{array}$ \\
\hline A. LATIN AMERICA & & & & \\
\hline 1. Andean Region & $73,189,000$ & 42,120 & 63,961 & 0.9 \\
\hline 2. Southern Cone & $44,155,000$ & 15,424 & 24,730 & 0.6 \\
\hline 3. Mexico & $69,994,000$ & 15,237 & 26,700 & 0.4 \\
\hline 4. Brazil & $126,377,000$ & 169,802 & 260,000 & 2.1 \\
\hline 5. Central America & $22,650,000$ & 1,706 & 3,302 & 0.1 \\
\hline $\begin{array}{l}\text { 6. Latinamerica } \\
\text { Caribbean }\end{array}$ & $25,179,000$ & 9,029 & 16,355 & 0.6 \\
\hline B. CARIBBEAN & $6,829,000$ & 9,945 & 16,969 & 2.5 \\
\hline C. NORTH AMERICA & $246,350,000$ & 1,854 & 3,728 & $0 \ldots$ \\
\hline TOTAL & $614,723,000$ & 265,117 & 415,745 & 0.7 \\
\hline
\end{tabular}

